\begin{tabular}{|c|l|}
\hline Title & High pressure densification and dielectric properties of perovskite type oxynitride SrT aO 2N \\
\hline Author(s) & Masubuchi, Yuji; Kawamura, Fumio; Taniguchi, Takashi; Kikkawa, Shinichi \\
\hline Citation & $\begin{array}{l}\text { Journal of the European Ceramic Society, 35(4), 1191-1197 } \\
\text { https://doi.org/10.1016/.jeurceramsoc.2014.10.028 }\end{array}$ \\
\hline Issue Date & 2015-04 \\
\hline Doc URL & http://hdl.handle.net/2115/58051 \\
\hline Type & article (author version) \\
\hline File Information & YMasubuchi-JEurCeramSoc-2015-35-1191-1197-1.pdf \\
\hline
\end{tabular}

Instructions for use 


\section{High pressure densification and dielectric properties of perovskite-type oxynitride $\mathrm{SrTaO}_{2} \mathrm{~N}$}

Yuji Masubuchi ${ }^{1}$, Fumio Kawamura ${ }^{2}$, Takashi Taniguchi ${ }^{2}$, and Shinichi Kikkawa ${ }^{1}$

Affiliations

${ }^{1}$ Faculty of Engineering, Hokkaido University, N13 W8, Kita-ku, Sapporo, 060-8628, Japan

${ }^{2}$ National Institute for Materials Science, 1-1 Namiki, Tsukuba, 305-0044, Japan

*Corresponding author: Y. Masubuchi; Address: Faculty of Engineering, Hokkaido University, N13 W8, Kita-ku, Sapporo 060-8628, Japan; Tel/Fax: +81-(0)11-706-6742/6740; E-mail: yuji-mas@eng.hokudai.ac.jp 


\section{Abstract}

Perovskite-type $\mathrm{SrTaO}_{2} \mathrm{~N}$ was densified using a belt-type high pressure apparatus at 2.5-7.7 GPa with and without sample heating. The relative density of the samples treated at $2.5 \mathrm{GPa}$ was $64 \%$ and was increased to $75 \%$ in those treated at 7.7 GPa without sample heating. The color of the compact changed from orange to brown with densification and the crystals were fractured to nanometer size grains. The density was increased up to $86 \%$ with heating above $800{ }^{\circ} \mathrm{C}$ at $7.7 \mathrm{GPa}$ and the sample color changed to black, accompanied by electrically conductive nature. The permittivity of compacts that were densified to a relative density of around $75 \%$ with heating at $600{ }^{\circ} \mathrm{C}$ and without sample heating were 200 and 90 at $100 \mathrm{~Hz}$, respectively.

Keywords: $\mathrm{SrTaO}_{2} \mathrm{~N}$, Perovskite oxynitride, High pressure densification, Dielectric property 


\section{Introduction}

Perovskite-type oxynitrides, $\mathrm{SrTaO}_{2} \mathrm{~N}$ and $\mathrm{BaTaO}_{2} \mathrm{~N}$ have attracted much attention since the report of their superior dielectric properties by Kim et al. in 2004 [1]. The bulk ceramics had a low relative density value around 55\% even after a powder compact is cold isostatically pressed (CIP) at $430 \mathrm{MPa}$ and sintered at $1020{ }^{\circ} \mathrm{C}$ in $\mathrm{NH}_{3}$ flow [1]. Their permittivity of several hundred was reported in the temperature range between 180 and $300 \mathrm{~K}$, with a relatively large dielectric loss $>1$ [1]. However there have been no other reports to support the interesting information. Two independent reports in 2011 indicate the presence of cis-type $\mathrm{TaO}_{4} \mathrm{~N}_{2}$ in $\mathrm{SrTaO}_{2} \mathrm{~N}$ from neutron diffraction data $[2,3]$. The cis-configuration of $\mathrm{TaO}_{4} \mathrm{~N}_{2}$ was maintained up to $1100{ }^{\circ} \mathrm{C}$ from high temperature neutron diffraction measurements [4].

To clarify the intrinsic dielectric properties of the oxynitride, highly densified $\mathrm{SrTaO}_{2} \mathrm{~N}$ ceramics were prepared by sintering at $1400{ }^{\circ} \mathrm{C}$ in $0.2 \mathrm{MPa}$ of $\mathrm{N}_{2}$ and subsequent annealing at $1000{ }^{\circ} \mathrm{C}$ in $\mathrm{NH}_{3}$ flow $[5,6] . \mathrm{SrCO}_{3}(2.5 \mathrm{wt} \%)$ was necessary as a sintering additive to compensate for the partial loss of SrO during high temperature sintering. The sample color changed from orange to black with sintering due to a slight loss of nitrogen, although the sintered ceramics was 
single phase of $\mathrm{SrTaO}_{2} \mathrm{~N}$. Less dense $\mathrm{SrTaO}_{2} \mathrm{~N}$ ceramics with relative density of $<85 \%$ recovered both the orange color, stoichiometric nitrogen content and electrical insulating behavior after the annealing in $\mathrm{NH}_{3}$. The nitrogen loss was not recovered in fully dense $\mathrm{SrTaO}_{2} \mathrm{~N}$ ceramics. The dielectric constant of $\mathrm{SrTaO}_{2} \mathrm{~N}$ changed in the range between 450 and 9000 with the relative density. The recovery in the post annealing was more difficult in the denser ceramics. Sintering with hot isostatic pressing (HIPping) at $1400{ }^{\circ} \mathrm{C}$ under $196 \mathrm{MPa}$ has also been applied to prepare highly densified $\mathrm{SrTaO}_{2} \mathrm{~N}$ ceramics [7]. The color of the $\mathrm{SrTaO}_{2} \mathrm{~N}$ ceramics also changed from brown to dark gray by HIPping and the original brown color was recovered by post-annealing in $\mathrm{NH}_{3}$. Neither high temperature sintering in nitrogen atmosphere nor HIPping suppressed the nitrogen loss from $\mathrm{SrTaO}_{2} \mathrm{~N}$. Thus, the sintered bodies must be post-annealed in $\mathrm{NH}_{3}$ to compensate for the nitrogen loss.

The thermal stability of perovskite-type oxynitrides has been investigated using a combination of thermogravimetry (TG) and mass spectroscopy (MS) in different atmospheres [8]. The oxidation reaction of $\mathrm{SrTaO}_{2} \mathrm{~N}$ begins at $480{ }^{\circ} \mathrm{C}$ in $10-20 \% \mathrm{O}_{2}$ diluted with $\mathrm{Ar}$ to produce $\mathrm{SrTaO}_{3.5}$. TG-MS measurement in $\mathrm{Ar}$ indicated $\mathrm{SrTaO}_{2} \mathrm{~N}$ released $\mathrm{N}_{2}$ gas above $1120{ }^{\circ} \mathrm{C}$ 
and the color was changed from orange to dark orange with black particles, although the perovskite phase was retained, as confirmed by X-ray diffraction (XRD) measurement. Thermal annealing of $\mathrm{SrTaO}_{2} \mathrm{~N}$ in an evacuated silica tube also partially released nitrogen and a secondary phase of rock-salt type $\mathrm{TaO}_{0.9}$ was formed together with the perovskite phase at $1100^{\circ} \mathrm{C}$ [6]. Thin film formation is another way of material shaping different from ceramic sintering. $\mathrm{SrTaO}_{2} \mathrm{~N}$ thin films were grown epitaxially on a $\mathrm{SrTiO}_{3}$ substrate by nitrogen plasma-assisted pulsed laser deposition method [9]. The compressively strained $\mathrm{SrTaO}_{2} \mathrm{~N}$ thin film was composed of small domains that exhibited ferroelectric response and a surrounding matrix that exhibited relaxor-type behavior.

Densification below the decomposition temperature is required to obtain highly densified $\mathrm{SrTaO}_{2} \mathrm{~N}$ ceramics without compositional change. The synthesis and sintering of metal nitrides have been examined on optical, magnetic, electronic and refractory materials, such as $\mathrm{GaN}, \mathrm{FeN}_{\mathrm{x}}, \mathrm{BN}$, and AIN [10-15]. However, little research has been conducted on synthesis of oxynitrides, e.g. $\mathrm{Ga}_{3} \mathrm{O}_{3} \mathrm{~N}$, and $\mathrm{REZrO} \mathrm{N}_{2} \mathrm{~N}(\mathrm{RE}=\mathrm{Pr}, \mathrm{Nd}$, and $\mathrm{Sm})$ suppressing a release of nitrogen under high pressure in the order of gigapascals $[16,17]$. Sintering of TaON has been investigated under high pressures of 3 and $5.5 \mathrm{GPa}$ at temperatures above 
$900{ }^{\circ} \mathrm{C}$ using a belt-type high pressure apparatus, while the green compacts were not densified but were oxidized to $\mathrm{Ta}_{2} \mathrm{O}_{5}$ during HIPping in $\operatorname{Ar}[18,19]$.

In this study, densified $\mathrm{SrTaO}_{2} \mathrm{~N}$ were prepared by using a belt-type high pressure apparatus to avoid the thermal decomposition under pressures of several gigapascals, with and without sample heating. The electrical properties of the densified ceramics were then investigated with respect to their phase decomposition.

\section{Experimental}

\subsection{High pressure and high temperature experiments}

$\mathrm{SrTaO}_{2} \mathrm{~N}$ was prepared by the ammonolysis reaction of $\mathrm{SrTaO}_{3.5}$, as reported in our previous paper [6]. The $\mathrm{SrTaO}_{2} \mathrm{~N}$ precursors were encapsulated in Pt or Au tubes (6 mm diameter, 2-3 mm height) under a dried Ar atmosphere. The encapsulated samples were set in the belt-type high pressure apparatus with a $\mathrm{NaCl}$ pressure transmitting medium and a graphite heater $[20,21]$. High pressure was applied in the range of 2.5-7.7 GPa at room temperature and the sample was then heated to temperatures in the range of $600-1000{ }^{\circ} \mathrm{C}$ and held for 30 or 60 min, as summarized in Table 1. After sintering under pressure, the 
sample was quenched to room temperature within a few minutes by turning off the heating power under the pressure. After release the pressure, the $\mathrm{SrTaO}_{2} \mathrm{~N}$ compacts were removed from the Pt (Au) wrapping.

\subsection{Characterization}

The crystalline phases were characterized using powder XRD (Ultima IV, Rigaku) with monochromatized $\mathrm{Cu}$ Ka radiation. XRD patterns were measured for the polished surface of the high pressure compacts. The relative densities of the compacts were determined using bulk densities measured from their dimensions and weight. Scanning electron microscopy (FE-SEM; JSM-6500F, Jeol) was used to observe the microstructure of the fractured surface. Transmission electron microscopy (TEM; JEM-2010, Jeol) observations were performed using thin slices prepared by focused ion beam milling (FIB; JIB-4600F, Jeol). The dielectric properties were measured using an LCR meter (4274A, Hewlett-Packard) in the frequency range from $10^{2}$ to $10^{6} \mathrm{~Hz}$ at room temperature with both surfaces of the compacts coated with silver paste as electrodes. Diffuse reflectance of the $\mathrm{SrTaO}_{2} \mathrm{~N}$ precursor and the high pressure compacts were measured with a UV-Vis spectrometer (V-550, Jasco). 


\section{Results and discussion}

\subsection{High pressure compacts obtained at ambient temperature}

$\mathrm{SrTaO}_{2} \mathrm{~N}$ compacts obtained at high pressures were single phase of perovskite as shown in Fig. 1. The diffraction lines broadened with the increase of pressure, while their lattice parameters were almost constant at room temperature, as summarized in Table 1 . The relative density of the compact formed at $2.5 \mathrm{GPa}$ was $64 \%$, which reached $75 \%$ at pressures above $5.5 \mathrm{GPa}$ without sample heating. The compact formed at $2.5 \mathrm{GPa}$ was bright orange colored, similar to the $\mathrm{SrTaO}_{2} \mathrm{~N}$ precursor powder. However, the color of the compact formed at 7.7 GPa had changed to dark brown, as shown in Fig. 2. Optical microscopic images of the fracture surfaces of the samples are shown in Fig. S1 of the Supporting Information (SI). As the pressure was increased, brown or black particles appeared together with the original orange particles. UV-Vis spectra for the powdered samples had a band gap energy of approximately 2.05 $\mathrm{eV}$ which was comparable with the reported value of $2.1 \mathrm{eV}$ [1]. The compacts became dark in color, but without impurity phases, although the crystallinity was lowered, which could be related to a microstructural change. A high density of 
defects on the particle surface was proposed as a reason for the optical change in perovskite-type tantalum oxynitrides [22].

The starting $\mathrm{SrTaO}_{2} \mathrm{~N}$ powder showed a coagulation of plate-like crystals and a particle size distribution from several micrometers to several hundreds of nanometers, as shown in Fig. 3(a). Then fracture surfaces of the high pressure compacts obtained at 2.5 and $7.7 \mathrm{GPa}$ without heating revealed dense microstructures where the morphology of the secondary particles was maintained. The primary particle size seems to be smaller than that of the original powder (Figs. 3(b) and 3(c)). Residual pores were evident in the TEM image of the compact obtained at $7.7 \mathrm{GPa}$, as depicted in Fig. 3(d), because no grain growth or sintering between $\mathrm{SrTaO}_{2} \mathrm{~N}$ grains occurred under the non-heating condition. The magnified image shown in Fig. 3(e) indicates that the grain surface was fractured into small particles of several tens of nanometers. The nanosized surface structure may be formed by inter-grain stress that arises during high pressure compaction. Similar diffraction line broadening has been reported for oxides, nitrides and carbides, where the grain size was reduced to the nanometer scale under microstructural strain $[13,23,24]$. The electron diffraction shown in Fig. 3(f) suggests that the fractured grains in Fig. 3(e) 
retained the perovskite-type crystal lattice. No amorphous halo pattern was observed or extra diffraction spots that would indicate the presence of a secondary phase. These observations suggest that the grain was fractured into nanosized particles during the room temperature compaction, as indicated by the XRD line broadening in Fig. 1, while the crystalline perovskite structure was still maintained.

\subsection{High pressure compacts obtained at high temperature}

High pressure compacts obtained at ambient temperature and pressures above $5.5 \mathrm{GPa}$ had a maximum relative density of $75 \%$. No secondary phases were observed in their XRD patterns; however, the diffraction lines were broadened due to the formation of nanosized particles that were responsible for the color change from orange to brown. To improve the density and crystallinity, high pressure sintering at high temperature was performed at a pressure of 7.7 GPa. Figure 4 shows that the relative density increased with temperatures above $800{ }^{\circ} \mathrm{C}$ and reached $83 \%$ at $1000{ }^{\circ} \mathrm{C}$. The product pressed at $600{ }^{\circ} \mathrm{C}$ was colored brown, similar to that obtained at ambient temperature. However, the color changed to black when sintered above $800{ }^{\circ} \mathrm{C}$. The sintered pellets were 
also single phase of perovskite structure, as shown in Fig. S2 in SI. The lattice parameters were almost comparable with those of the powder precursor but became slightly smaller along the a-axis with the increased sintering temperature under pressure of $7.7 \mathrm{GPa}$ (Table 1 ). Fracture surface of the pellet obtained at $600{ }^{\circ} \mathrm{C}$ was almost similar to that of the high pressure compact obtained without heating as shown in Fig. 5(a). However, sintering at $1000{ }^{\circ} \mathrm{C}$ slightly disrupted the particles to make a denser morphology in Fig. 5(b). The diffuse reflectance of the black pellets sintered above $800{ }^{\circ} \mathrm{C}$ was reduced in the near infrared region due to the appearance of electrical conductive nature in the sintered pellets as shown in Fig. S3 in SI. Dense phase is stabilized under high pressure as in the case of graphite to diamond phase transition. The observed lattice shrinkage was also induced by the application of high pressure, and this shrinkage may be compensated by the partial loss of nitrogen when the high pressure was released.

\subsection{Dielectric property of the high pressure compacts}

Figure 6 shows complex impedance plots for the high pressure compacts. Insulative characteristics are suggested by observation of only a large 
partial semi-circle for the compacts obtained under pressure of 2.5 and $7.7 \mathrm{GPa}$ at room temperature and that formed at $600{ }^{\circ} \mathrm{C}$ under $7.7 \mathrm{GPa}$. The compacts had slightly lower relative density below $75 \%$, and the sample color was orange or brown. At higher heating temperature above $800{ }^{\circ} \mathrm{C}$ and at $7.7 \mathrm{GPa}$, the sintered pellets were black and the complex impedance plots were semi-circles. The resistivities were estimated from the intersection with the real axis and were $25 \mathrm{M} \Omega \mathrm{cm}$ and $12 \mathrm{k} \Omega \mathrm{cm}$ for the pellets sintered at $800{ }^{\circ} \mathrm{C}$ and $1000{ }^{\circ} \mathrm{C}$, respectively. The conductivity may be related to a partial loss of nitrogen and the formation of rock-salt type $\mathrm{TaO}_{0.9}$ impurity, as reported in our previous paper [6]. Black colored conductive pellets were previously obtained when $\mathrm{SrTaO}_{2} \mathrm{~N}$ was sintered with a $\mathrm{SrCO}_{3}$ additive at high temperatures above $1300{ }^{\circ} \mathrm{C}$ under a 0.2 $\mathrm{MPa} \mathrm{N} \mathrm{N}_{2}$ atmosphere or when HIPped above $1200{ }^{\circ} \mathrm{C}$ at $196 \mathrm{MPa}$ [5-7]. The $\mathrm{TaO}_{0.9}$ impurity phase has also appeared in powder compacts annealed at $1100{ }^{\circ} \mathrm{C}$ in a silica tube under vacuum [6]. Nitrogen release from $\mathrm{SrTaO}_{2} \mathrm{~N}$ and thermal decomposition of the oxynitride have also been confirmed in a temperature range between $1120^{\circ} \mathrm{C}$ and $1200^{\circ} \mathrm{C}$ by thermal analysis with mass spectroscopic analysis [8]. Both decomposed products contained black particles due to the presence of the reduced $\mathrm{Ta}^{5+}$ species, and which also indicates the 
conductive nature of the product. The color of pellets sintered under a high pressure of $7.7 \mathrm{GPa}$ was changed to black above $800{ }^{\circ} \mathrm{C}$, which is approximately $200{ }^{\circ} \mathrm{C}$ lower than the decomposition temperature of $\mathrm{SrTaO}_{2} \mathrm{~N}$ in Ar or vacuum. The slight shrinkage of the unit cell volume could be related to partial decomposition and the release of nitrogen. Pressure-induced phase decomposition has been reported in many oxides with various crystal structures $[25,26]$. The $\mathrm{FeTiO}_{3}$ perovskite-type oxide (as a high pressure polymorph) was also decomposed into a mixture of rock-salt type "FeO" and $\mathrm{TiO}_{2}$ at high pressure above $67 \mathrm{GPa}[27,28]$. The high pressure-induced decomposition can be understood by the formation of a denser assemblage of the decomposed oxides that is favorable at high pressure rather than the parent ternary oxide. Pressure-induced phase decomposition has also been suggested in ternary nitride based on density functional calculations [29]. $\mathrm{SrTaO}_{2} \mathrm{~N}$ has a theoretical density of $7.95 \mathrm{~g} / \mathrm{cm}^{3}$ [2], which is less dense than those of simple tantalum oxides and nitrides such as $9.93 \mathrm{~g} / \mathrm{cm}^{3}$ for $\mathrm{Ta}_{3} \mathrm{~N}_{5}$ [30], $8.31 \mathrm{~g} / \mathrm{cm}^{3}$ for $\mathrm{Ta}_{2} \mathrm{O}_{5}$ [31] and around $15 \mathrm{~g} / \mathrm{cm}^{3}$ for rock-salt type TaO and TaN [32,33]. Rock-salt type $\mathrm{TaO}_{0.9}$ has been reported to appear as a high temperature impurity phase in $\mathrm{SrTaO}_{2} \mathrm{~N}$ [6]. High pressure inducing microstructural stress on the $\mathrm{SrTaO}_{2} \mathrm{~N}$ 
grains decreases its thermal stability because higher density phases such as TaO or TaN with theoretical densities around $15 \mathrm{~g} / \mathrm{cm}^{3}$ may stabilize under the high pressure rather than $\mathrm{SrTaO}_{2} \mathrm{~N}$ with a lower density of $7.9 \mathrm{~g} / \mathrm{cm}^{3}$.

Permittivity and dielectric loss (tanঠ) were measured for the orange and brown insulative pellets. The relative dielectric constants for the high pressure compacts obtained at 2.5 and $7.7 \mathrm{GPa}$ without sample heating were 60 and 90 , respectively as shown in Fig. 7 . Heating at $600{ }^{\circ} \mathrm{C}$ under a pressure at $7.7 \mathrm{GPa}$ significantly increased the dielectric constant to 200 at $100 \mathrm{~Hz}$. The dielectric loss for the sintered pellet were slightly increased above $\tan \delta>0.1$. Their permittivity had a small frequency dependence. The permittivity and low dielectric loss values measured for the high pressure compacts were comparable to those of previously measured for dense $\mathrm{SrTaO}_{2} \mathrm{~N}$ ceramics sintered at $1450{ }^{\circ} \mathrm{C}$ under $0.2 \mathrm{MPa} \mathrm{N}_{2}$ atmosphere with subsequent post-annealing at $1000{ }^{\circ} \mathrm{C}$ in $\mathrm{NH}_{3}$ flow [6]. High pressure compaction at low heating temperatures and at ambient temperature densified the thermally unstable $\mathrm{SrTaO}_{2} \mathrm{~N}$ up to a relative density of $75 \%$, while conductive behavior appeared in the high pressure compacts sintered above $800^{\circ} \mathrm{C}$, which is $200^{\circ} \mathrm{C}$ lower than the decomposition temperature of $\mathrm{SrTaO}_{2} \mathrm{~N}$ under vacuum or Ar flow. 


\section{Conclusion}

High pressure densification was investigated for perovskite-type $\mathrm{SrTaO}_{2} \mathrm{~N}$ with and without sample heating. The products were phase pure perovskites and the relative density was increased for samples pressed at ambient temperature from 64 at $2.5 \mathrm{GPa}$ to $75 \%$ at $7.7 \mathrm{GPa}$. In addition to the densification, the sample color changed from orange to brown and the crystallinity was decreased due to the formation of nanoparticles, while the perovskite structure was retained. Heating above $800{ }^{\circ} \mathrm{C}$ at $7.7 \mathrm{GPa}$ promoted densification up to $85 \%$ accompanied by a slight contraction of the crystal lattice. The sintered ceramics were black and exhibited electrical conductivity due to a partial loss of nitrogen. The decomposition reaction may occur under high pressure sintering above $800^{\circ} \mathrm{C}$, which is lower than the temperature of thermal decomposition at ambient pressure or in a vacuum. The presence of crystalline phases that are denser than $\mathrm{SrTaO}_{2} \mathrm{~N}$ may depress the stability of the perovskite phase at high pressure. High pressure compacts with a relative density of $75 \%$ prepared at $600{ }^{\circ} \mathrm{C}$ and $7.7 \mathrm{GPa}$ were insulative and had a permittivity of 200 $(100 \mathrm{~Hz})$ at room temperature. 


\section{Acknowledgement}

This work was partly supported by a Grant-in Aid for Scientific Research (A) (No.

24245039) from the Japan Society for the Promotion of Science (JSPS). Some TEM observations was conducted at Hokkaido University, supported by the Nano-technology Platform Program of the Ministry of Education, Culture, Sports, Science and Technology (MEXT), Japan. Y. M. acknowledges financial support from the Murata Science Foundation. 


\section{References}

[1] Kim YI, Woodward PM, Baba-Kishi KZ, Tai CW. Characterization of the structural, optical, and dielectric properties of oxynitride perovskites $\mathrm{AMO}_{2} \mathrm{~N}(\mathrm{~A}=$ $\mathrm{Ba}, \mathrm{Sr}, \mathrm{Ca} ; \mathrm{M}=\mathrm{Ta}, \mathrm{Nb})$. Chem Mater 2004;16:1267-76.

[2] Zhang YR, Motohashi T, Masubuchi Y, Kikkawa S. Local anionic ordering and anisotropic displacement in dielectric perovskite $\mathrm{SrTaO}_{2} \mathrm{~N}$. J Ceram Soc Jpn 2011;119:581-6.

[3] Yang M, Oró-Solé J, Rodgers JA, Jorge AB, Fuertes A, Attfield JP. Anion order in perovskite oxynitrides. Nat Chem 2011;3:47-52.

[4] Clark L, Oró-Solé J, Knight KS, Fuertes A, Attfield JP. Thermally robust anion-chain order in oxynitride perovskites. Chem Mater 2013;25:5004-11.

[5] Zhang YR, Motohashi T, Masubuchi Y, Kikkawa S. Sintering and dielectric properties of perovskite $\mathrm{SrTaO}_{2} \mathrm{~N}$ ceramics. J Eur Ceram Soc 2012;32:1269-74. [6] Sun SK, Zhang YR, Masubuchi Y, Motohashi T, Kikkawa S. Additive sintering, postannealing, and dielectric properties of $\mathrm{SrTaO}_{2} \mathrm{~N}$. J Am Ceram Soc 2014;97:1023-7. 
[7] Zhang YR, Masubuchi Y, Motohashi T, Kikkawa S, Hirota K. Hot isostatic press sintering and dielectric properties of $\mathrm{SrTaO}_{2} \mathrm{~N}$ ceramics. Ceram Int 2013;39:3377-80.

[8] Aguiar R, Logvinovich D, Weidenkaff A, Reller A, Ebbinghaus SG. Thermal oxidation of oxynitride perovskites in different atmospheres. Thermochim Acta 2008;471:55-60.

[9] Oka D, Hirose Y, Kamisaka H, Fukumura T, Sasa K, Ishii S, Matsuzaki H, Sato Y, Ikuhara Y, Hasegawa T. Possible ferroelectricity in perovskite oxynitride $\mathrm{SrTaO}_{2} \mathrm{~N}$ epitaxial thin films. Sci Rep 2014;4:4987/1-6.

[10] Kawamura F, Watanabe K, Takeda T, Taniguchi T. Synthesis of high-crystallinity cubic-GaN nanoparticles using the Na flux method - A proposed new usage for a belt-type high-pressure apparatus. J Cryst Growth $2011 ; 321: 100-5$

[11] Saitoh $\mathrm{H}$, Utsumi W, Kaneko $\mathrm{H}$, Aoki $\mathrm{K}$, Synthesis of $\mathrm{Al}_{\mathrm{x}} \mathrm{Ga}_{1-\mathrm{x}} \mathrm{N}$ alloy by solid-phase reaction under high pressure. Jpn J Appl Phys 2004;43:L981-3.

[12] Dzivenko DA, Zerr A, Miehe G, Riedel R. Synthesis and properties of oxygen-bearing c- $\mathrm{Zr}_{3} \mathrm{~N}_{4}$ and c- $\mathrm{Hf}_{3} \mathrm{~N}_{4}$. J Alloys Compd 2009;480:46-9. 
[13] Takagi K, Akada M, Ozaki K, Kobayashi N, Ogawa T, Ogata Y, Takahashi M. High-pressure sintering behavior of $\alpha$ "- $\mathrm{Fe}_{16} \mathrm{~N}_{2}$ nanopowder. J Appl Phys 2014;115:103905/1-5.

[14] Li XL, Ma HA, Zheng YJ, Liu Y, Zuo GH, Liu WQ, Li JG, Jia X. AIN ceramics prepared by high-pressure sintering with $\mathrm{La}_{2} \mathrm{O}_{3}$ as a sintering aid. J Alloys Compd 2008;463:412-6.

[15] Taniguchi T, Akaishi M, Yamaoka S. Sintering of cubic boron nitride without additives at 7.7 GPa and above $2000{ }^{\circ} \mathrm{C}$. J Mater Res 1999;14:162-9.

[16] Huppertz H, Hering SA, Zvoriste CE, Lauterbach S, Oeckler O, Riedel R, Kinski I. High-pressure synthesis, electron energy-loss spectroscopy investigation, and single crystal structure determination of a spinel-type gallium oxonitride $\mathrm{Ga}_{2.79 \square 0.21}\left(\mathrm{O}_{3.05} \mathrm{~N}_{0.76} \square_{0.19}\right)$. Chem Mater 2009;21:2101-7.

[17] Yang M, Rodgers JA, Middler LC, Oró-Solé J, Jorge AB, Fuertes A, Attfield JP. Direct solid-state synthesis at high pressures of new mixed-metal oxynitrides: $\mathrm{RZrO}_{2} \mathrm{~N}(\mathrm{R}=\mathrm{Pr}, \mathrm{Nd}$, and Sm). Inorg Chem 2009;48:11498-500.

[18] Matizamhuka WR, Herrmann M, Sigalas I, Sempf K. Preparation, hardness, and fracture toughness of tantalum oxynitride ceramics. J Am Ceram Soc 2007;90:2280-2. 
[19] Matizamhuka WR, Sigalas I, Herrmann M. Synthesis, sintering and characterisation of TaON materials. Ceram Int 2008;34:1481-6.

[20] Fukunaga O, Takeuchi S, Taniguchi T. High-pressure synthesis of cubic BN using Fe-Mo-Al and Co-Mo-Al alloy solvents. Diamond Relat Mater $2011 ; 20: 752-5$

[21] Taniguchi T, Yamaoka S. Spontaneous nucleation of cubic boron nitride single crystal by temperature gradient method under high pressure. J Cryst Growth 2001;222:549-57.

[22] Kim YI. Effects of $\mathrm{KCl}$ flux on the morphology, anion composition, and chromaticity of perovskite oxynitrides, $\mathrm{CaTaO}_{2} \mathrm{~N}, \mathrm{SrTaO}_{2} \mathrm{~N}$, and $\mathrm{LaTaON}_{2}$. Ceram Int 2014;40:5275-81.

[23] Nadeau JS. Very high pressure hot pressing of silicon carbide. Am Ceram Soc Bull 1973;52:170-4.

[24] Machon D, Sinitsyn VV, Dmitriev VP, Bdikin IK, Dubrovinsky LS, Kuleshov IV, Ponyatovsky EG, Weber HP. Structural transition in $\mathrm{Cu}_{2} \mathrm{O}$ at pressures up to 11 GPa. J Phys Condens Matter 2003;15:7227-35.

[25] Marezio M, Remeika JP, Jayaraman. A. High-pressure decomposition of synthetic garnet. J Chem Phys 1966;45:1821-4. 
[26] Ravindran TR, Arora AK, Mary TA, High-pressure Raman spectroscopic study of zirconium tungstate. J Phys Condens Matter 2001;13:11573-88.

[27] Leinenweber K, Utsumi W, Tsuchida Y, Yagi T, and Kurita K. Unquenchable high-pressure perovskite polymorphs of $\mathrm{MnSnO}_{3}$ and $\mathrm{FeTiO}_{3}$. Phys Chem Mater 1991;18:244-50.

[28] Nishio-Hamane D, Yagi T, Ohshiro M, Niwa K, Seto Y. Decomposition of perovskite $\mathrm{FeTiO}_{3}$ into wüstite $\mathrm{Fe}_{1-\mathrm{x}} \mathrm{Ti}_{0.5 \times} \mathrm{O}$ and orthorhombic $\mathrm{FeTi}_{3} \mathrm{O}_{7}$ at high pressure. Phys Rev B, 2010;82:092103/1-4.

[29] Römer SR, Braun C, Oeckler O, Schmidt PJ, Kroll P, Schnick W. HP-Ca ${ }_{2} \mathrm{Si}_{5} \mathrm{~N}_{8}$ - A new high-pressure nitridosilicate: synthesis, structure luminescence, and DFT calculations. Chem Eur J 2008;14:7892-902.

[30] Strähle J. Die kristallstruktur des tantal(V)-nitrides $\mathrm{Ta}_{3} \mathrm{~N}_{5}$. Z Anorg Allg Chem 1973;402:47-57.

[31] Stephenson NC, Roth RS. Structural systematics in the binary system $\mathrm{Ta}_{2} \mathrm{O}_{5}$ $-\mathrm{WO}_{3}$. V. The structure of the low-temperature form of tantalum oxide $L-\mathrm{Ta}_{2} \mathrm{O}_{5}$. Acta Crystallogr 1971;B27:1037-44.

[32] Schönberg N. An x-ray investigation of the tantalum-oxygen system. Acta Chem Scand 1954;8:240-5. 
[33] Brauer G, Kiliani W. Darstellung und kristallstruktur von niob-tantal-nitridphasen (Nb,Ta) $\mathrm{N}_{\sim 1}$. Z Anorg Allgem Chem 1979;452:17-26. 
Table 1 Lattice parameters and relative densities of $\mathrm{SrTaO}_{2} \mathrm{~N}$ compacts

\begin{tabular}{ccccc}
\hline Pressure $/$ & Temp. $/{ }^{\circ} \mathrm{C}$ & \multicolumn{2}{c}{ Lattice parameters } & Relative \\
\cline { 3 - 4 } $\mathrm{GPa}$ & (duration / min.) & $\mathrm{a} / \mathrm{nm}$ & $c / \mathrm{nm}$ & density, $\rho / \%$ \\
\hline \multicolumn{2}{c}{$\mathrm{SrTaO}_{2} \mathrm{~N}$ powder } & $0.56972(1)$ & $0.80786(2)$ & - \\
2.5 & - & $0.56973(4)$ & $0.8082(1)$ & $64(1)$ \\
5.5 & - & $0.56983(6)$ & $0.8082(2)$ & $76(1)$ \\
7.7 & - & $0.56985(6)$ & $0.8083(2)$ & $75(2)$ \\
7.7 & $600(60)$ & $0.56974(9)$ & $0.8085(2)$ & $71(2)$ \\
7.7 & $800(60)$ & $0.56963(1)$ & $0.8083(1)$ & $82(1)$ \\
7.7 & $1000(30)$ & $0.56952(3)$ & $0.8084(1)$ & $83(2)$ \\
\hline
\end{tabular}


Figure captions

Figure 1. XRD patterns for the $\mathrm{SrTaO}_{2} \mathrm{~N}$ (a) powder and high pressure compacts obtained at (b) 2.5, (c) 5.5, and (d) $7.7 \mathrm{GPa}$ and at ambient temperature.

Figure 2. Relative density of high pressure compacts obtained at ambient temperature. Inset photographs indicate the color of the compacts.

Figure 3. SEM images of the $\mathrm{SrTaO}_{2} \mathrm{~N}$ starting powder (a) and fracture surfaces of the high pressure compacts obtained at (b) 2.5 and (c) $7.7 \mathrm{GPa}$. TEM image of the compact obtained at (d) $7.7 \mathrm{GPa}$ and (e) a magnified image of the area indicated by a red square in (d), and (f) an electron diffraction pattern.

Figure 4. Relative density of the high pressure compacts as a function of the heating temperature. Inset photographs indicate the color of the compacts.

Figure 5. SEM images of the high pressure compacts sintered at $600{ }^{\circ} \mathrm{C}(\mathrm{a})$ and $1000^{\circ} \mathrm{C}(\mathrm{b})$ under a pressure of $7.7 \mathrm{GPa}$. 
Figure 6. Complex impedance plots for the high pressure compacts. The inset shows an expanded low frequency plot for the compacts.

Figure 7. Frequency dependence of the permittivity and dielectric loss for the high pressure compacts. 
Figure 1, Y. Masubuchi, et al.,

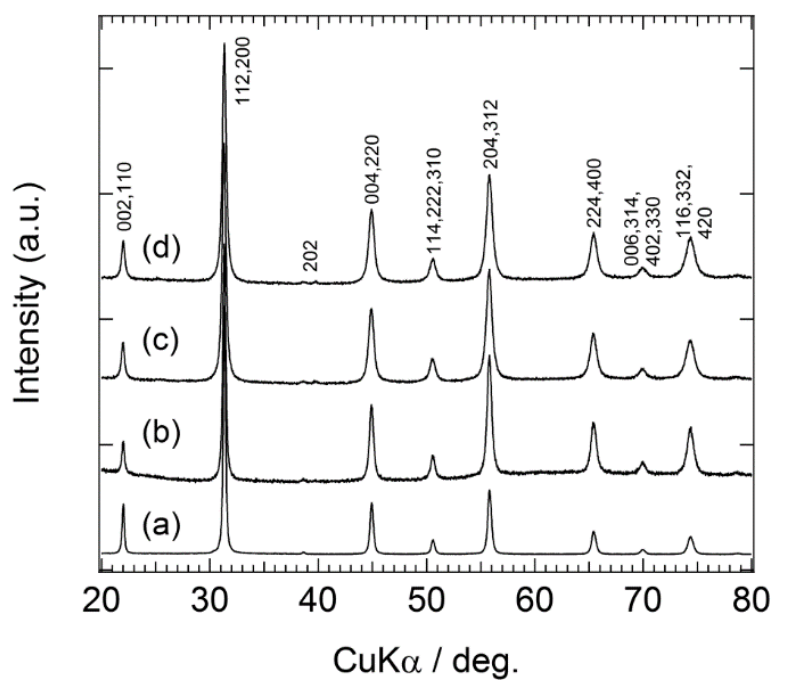


Figure 2, Y. Masubuchi, et al.,

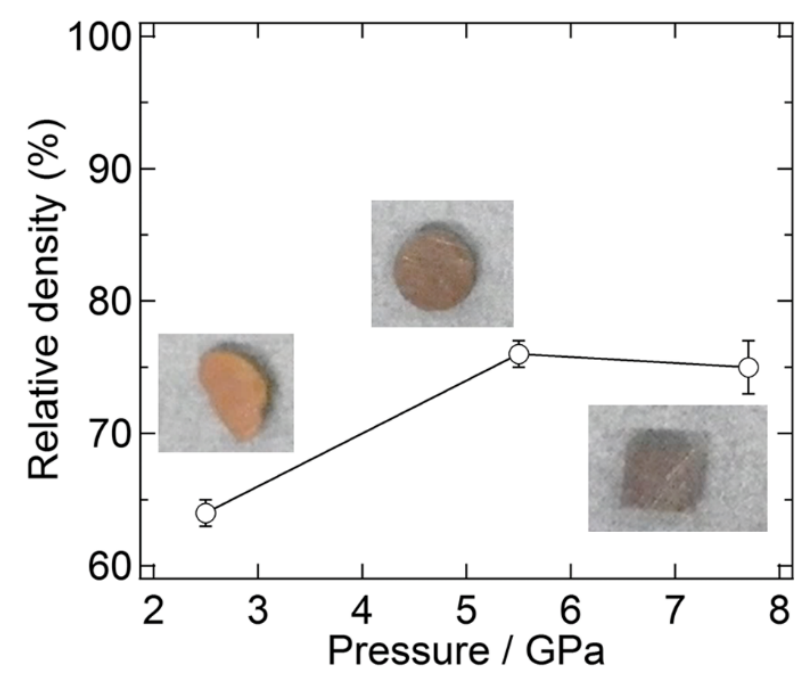


Figure 3, Y. Masubuchi, et al.,
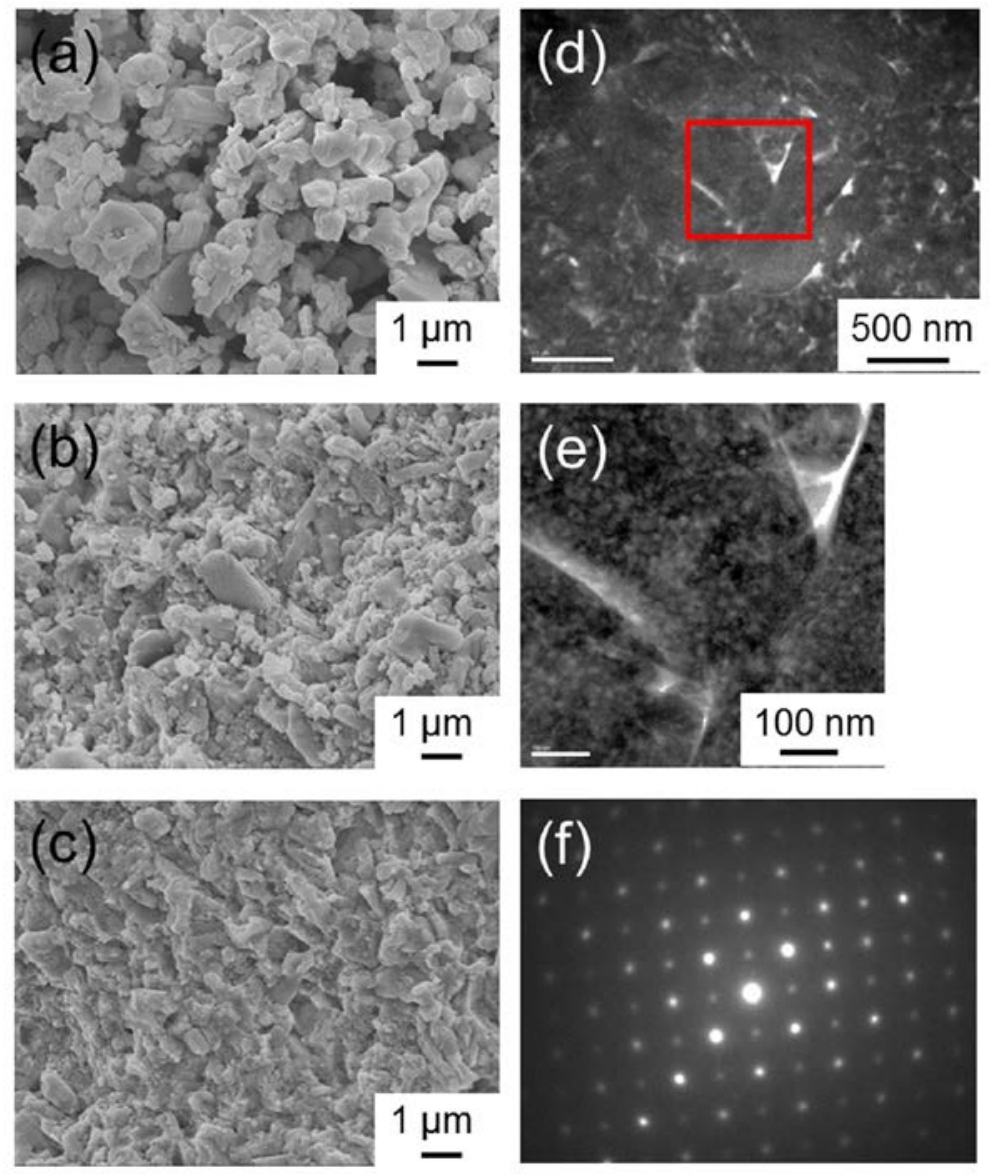
Figure 4, Y. Masubuchi, et al.,

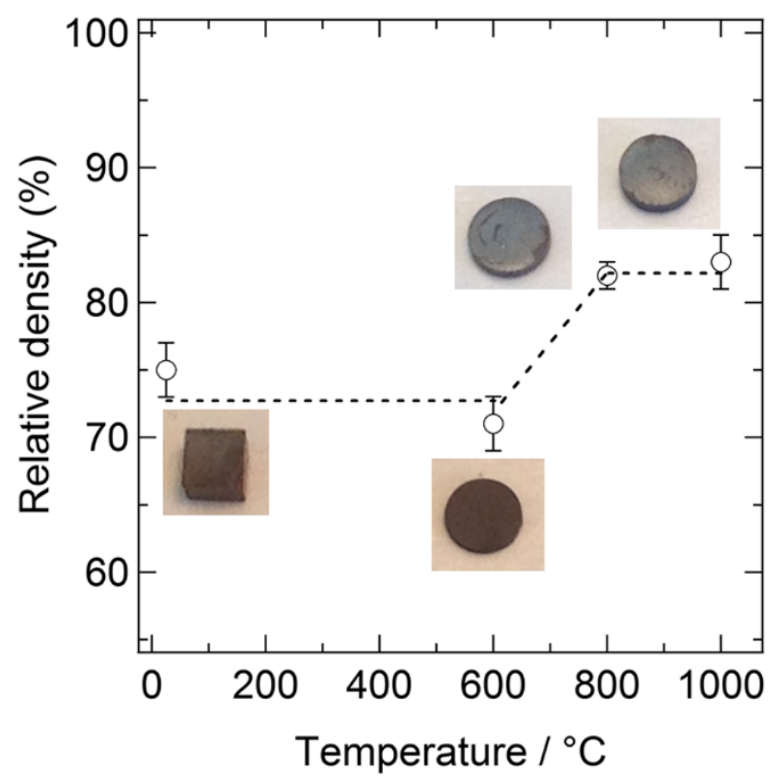


Figure 5, Y. Masubuchi
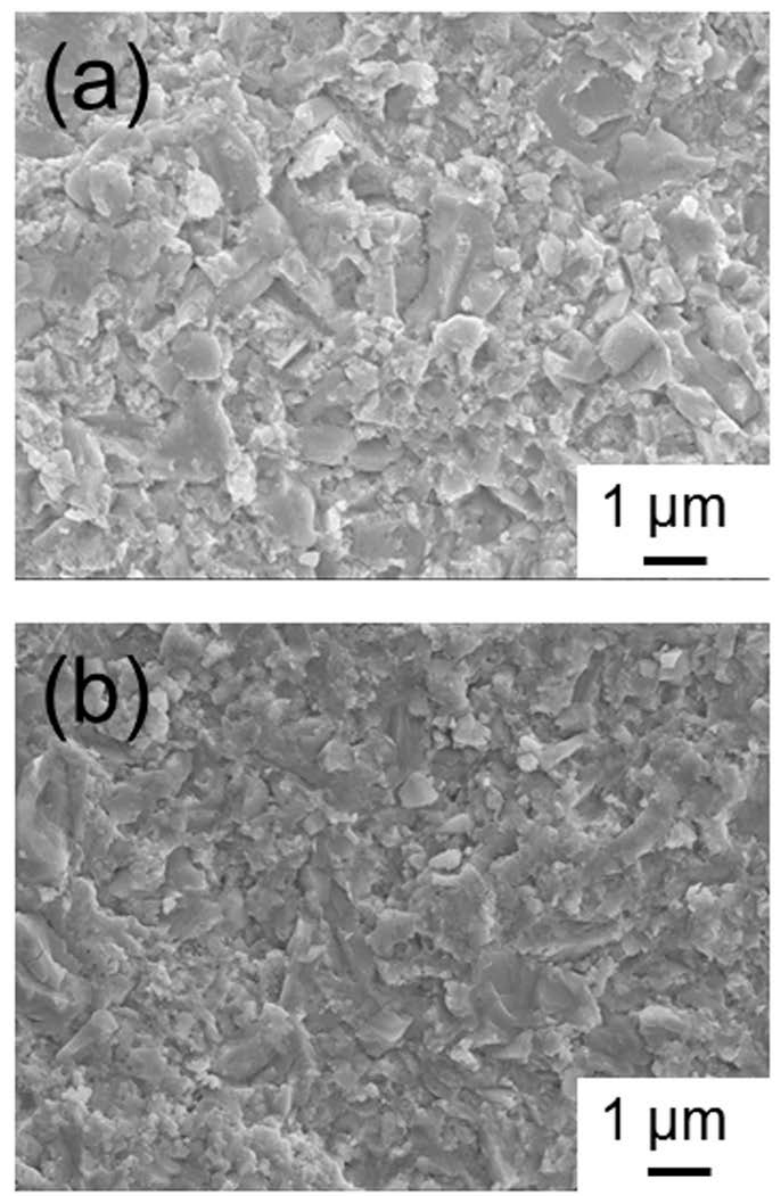
Figure 6, Y. Masubuchi, et al.,

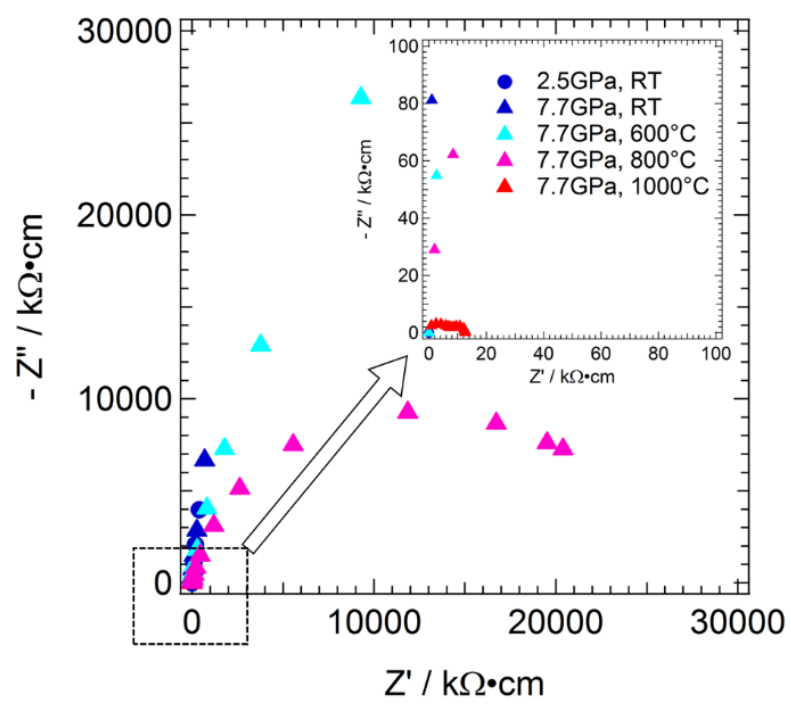


Figure 7, Y. Masubuchi, et al.,

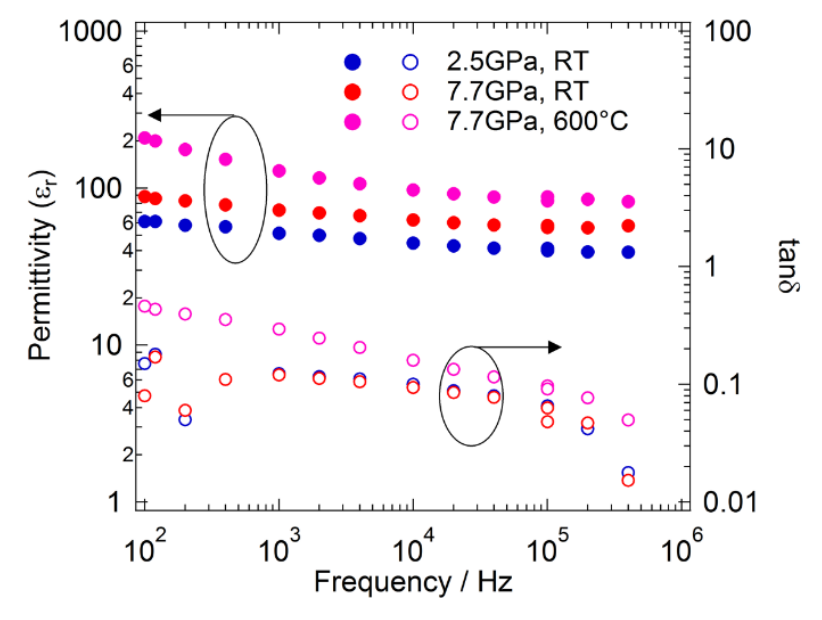

